\title{
Attitudes toward the SARS-CoV-2 Vaccine: Results from the Saudi Residents' Intention to Get Vaccinated against COVID-19 (SRIGVAC) Study
}

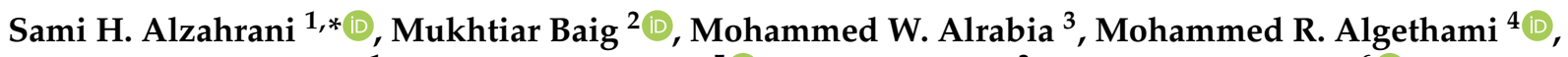 \\ Meshari M. Alhamdan ${ }^{1}$, Nabil A. Alhakamy ${ }^{5}$ (D) Hani Z. Asfour ${ }^{3}$ and Tauseef Ahmad ${ }^{6}$ (D) \\ 1 Family Medicine Department, Faculty of Medicine, King Abdulaziz University, P.O. Box 80205, \\ Jeddah 21589, Saudi Arabia; malhamdan1@kau.edu.sa \\ 2 Faculty of Medicine, King Abdulaziz University, Jeddah 21589, Saudi Arabia; mbbaig@kau.edu.sa \\ 3 Department of Medical Microbiology and Parasitology, Faculty of Medicine, King Abdulaziz University, \\ Jeddah 21589, Saudi Arabia; mwalrabia@kau.edu.sa (M.W.A.); hasfour@kau.edu.sa (H.Z.A.) \\ 4 Preventive Medicine and Public Health Resident, Ministry of Health, Jeddah 21577, Saudi Arabia; \\ abo-reada-511@hotmail.com \\ 5 Department of Pharmaceutics, Faculty of Pharmacy, King Abdulaziz University, Jeddah 21589, Saudi Arabia; \\ nalhakamy@kau.edu.sa \\ 6 Department of Epidemiology and Health Statistics, School of Public Health, Southeast University, \\ Nanjing 210096, China; tahmad@seu.edu.cn \\ * Correspondence: salzahrani4@kau.edu.sa; Tel.: +966-500004062
}

\section{check for} updates

Citation: Alzahrani, S.H.; Baig, M.; Alrabia, M.W.; Algethami, M.R.; Alhamdan, M.M.; Alhakamy, N.A.; Asfour, H.Z.; Ahmad, T. Attitudes toward the SARS-CoV-2 Vaccine: Results from the Saudi Residents' Intention to Get Vaccinated against COVID-19 (SRIGVAC) Study. Vaccines 2021, 9, 798. https://doi.org/ $10.3390 /$ vaccines 9070798

Academic Editor: Carlo Signorelli

Received: 28 May 2021

Accepted: 15 July 2021

Published: 18 July 2021

Publisher's Note: MDPI stays neutral with regard to jurisdictional claims in published maps and institutional affiliations.

Copyright: (c) 2021 by the authors. Licensee MDPI, Basel, Switzerland. This article is an open access article distributed under the terms and conditions of the Creative Commons Attribution (CC BY) license (https:// creativecommons.org/licenses/by/ $4.0 /)$.
Abstract: Vaccine uptake could influence vaccination efforts to control the widespread COVID19 pandemic; however, little is known about vaccine acceptance in Saudi Arabia. The present study aimed to assess the Saudi public's intent to get vaccinated against COVID-19 and explore the associated demographic determinants of their intentions as well as the reasons for vaccine hesitancy. A cross-sectional, web-based survey was distributed to public individuals in Saudi Arabia between 25 December 2020 and 15 February 2021. Participants were asked if they were willing to get vaccinated, and the responses, along with demographic data were entered into a multinomial logistic regression model to assess the relative risk ratio (RRR) for responding "no" or "unsure" versus "yes". Among 3048 participants (60.1\% female, $89.5 \%$ Saudi), 52.9\% intend to get vaccinated, $26.8 \%$ were unsure, and $20.3 \%$ refused vaccination. Vaccine hesitancy was significantly higher among females $(\mathrm{RRR}=2.70, p<0.0001)$ and those who had not been recently vaccinated for influenza $(\mathrm{RRR}=2.63$, $p<0.0001)$. The likelihood was lower among Saudis ( $R R R=0.49, p<0.0001)$, those with less than a secondary education $(\mathrm{RRR}=0.16, p<0.0001)$, perceived risks of COVID-19, and residents of the southern region $(\mathrm{RRR}=0.46, p<0.0001)$. The most often cited reasons for hesitancy were short clinical testing periods and concerns about adverse events or effectiveness. Vaccine hesitancy is mediated by many demographic factors and personal beliefs. To address vaccine-related concerns and amend deeply rooted health beliefs, communication should provide transparent information.

Keywords: vaccination; hesitancy; COVID-19; Saudi Arabia

\section{Introduction}

The widespread new strains of the coronavirus (SARS-CoV-2) have represented a major health burden globally. As of 28 February 2021, the novel coronavirus disease (COVID-19) has affected more than 113 million individuals and caused more than 2.5 million deaths worldwide [1]. In Saudi Arabia, more than 377,000 confirmed cases and more than 6400 COVID-19-related deaths have been reported across the Kingdom [2]. Globally, COVID-19 has caused widespread havoc, and the consequences have impacted people on financial, social, mental, and personal levels [3,4]. 
Indeed, Saudi Arabia is an important destination for millions of Muslims for Umrah and Hajj; therefore, it was among the first countries to implement strict precautionary measures to control the spread of the epidemic [5]. The success of public health efforts in different regions will largely depend on providing acquired immunity to a considerable proportion of the population, which has been ideally estimated at 67\% [6]. Although the duration and degree of protection from vaccines remains enigmatic, widespread vaccination seems to be the most effective method of controlling the pandemic. The development of a COVID-19 vaccine has brought a glimmer of hope to the world. Vaccination not only decreases the incidence of disease but also protects non-immunized people in the general population [7].

However, vaccine acceptance and trust in the effectiveness and safety of immunization will play a central role in whether we attain the ideal coverage required to reach so-called herd immunity. Early data from European countries (April 2020) have indicated that the hesitancy regarding a prospective vaccine was prevalent among $26 \%$ of adults, and approximately the same proportion of hesitant individuals has also been reported in the United States [8]. Furthermore, a subsequent cross-sectional investigation carried out in July 2020 showed that vaccine rejection was reported among about one-third of adult populations [9]. Notably, there were specific demographic variations in the patterns of vaccine acceptance, with a greater likelihood of vaccine refusal among females and those with low incomes and low levels of education, as well as those who had not been vaccinated against influenza in the preceding year [9-11].

Based on the aforementioned observations, it is necessary to understand individuals' attitudes about vaccination and identify the barriers that may affect their decisions in the context of the COVID-19 vaccine. As of 3 March 2021, more than 295,000 individuals have received the COVID-19 vaccination in Saudi Arabia [2]. To the best of our knowledge, only one national study has been conducted so far to assess participants' willingness to get the vaccine [12]; the study involved four major cities and was carried out before the initiation of the vaccination program. With the increased body of data regarding the new vaccine in the media and from other information sources, perceptions and attitudes of the public might have changed [13]. Thus, the intention to receive the vaccine should be a matter of ongoing research. In the present study, we aimed to explore participants' willingness to get vaccinated against COVID-19. Additionally, we assessed the demographic determinants of their intentions and the reasons for their vaccine hesitancy.

\section{Materials and Methods}

\subsection{Participants and Survey Administration}

The Saudi Residents' Intention to Get Vaccinated Against COVID-19 (SRIGVAC) study was a cross-sectional survey of adults residing in Saudi Arabia. Participants were asked to fill out a structured questionnaire on a specifically designated platform (Google Forms) between 25 December 2020 and 15 February 2021. The questionnaire was adapted from previously published studies $[9,14,15]$ and then circulated electronically using various social media platforms. The first screen informed potential participants about the aims of the survey and presented an informed consent notice. They were then advised that by clicking on the accept button, they were agreeing to the informed consent and could continue on to complete the survey.

The questionnaire was in English, but our participants were mostly Arabic speaking, so two bilingual translators handled the bidirectional translation. The questionnaire was then modified accordingly to improve respondents' comprehension while maintaining the content and meaning. A pilot test was conducted with 50 people from the general population to check the questionnaire's understandability, and it was then further modified accordingly. Questionnaire reliability was $82 \%$ according to Chronbach's alpha. Two senior faculty members and a medical educationist reviewed the questionnaire's construct and content validity, and it was further changed as suggested. We employed the snowball technique for data collection because of the COVID-19 restrictions. The calculated sample size was 770, and we further inflated that number to get valid and generalizable results. 


\subsection{Measures}

Participants' intentions regarding vaccination were measured using the item "If the COVID-19 vaccine became available in your country and was provided to you by the government free of charge, would you get vaccinated?" The responses were collected on a five-point Likert scale of strongly disagree, disagree, unsure, agree, and strongly agree. Positive responses (agree and strongly agree) and negative responses (disagree and strongly disagree) were then combined into yes and no categories for the subsequent analysis. Reasons for vaccination hesitancy were assessed using 11 items related to the vaccine itself (adverse events, lack of efficacy, etc.), lack of trust in pharmaceutical companies (in manufacturing, vaccine development, and clinical testing), or misperceptions about COVID-19 infection (belief that it is a harmless disease or having a preference for natural immunity). Data related to participant characteristics were also collected, including age, gender, nationality, household size, geographic location, education level, monthly income, and employment status. Additionally, the medical histories of chronic illness or COVID-19 infection were collected from respondents, and any history of COVID-19 infections among friends and family were also collected. For the geographic location variable, participants had to initially select a response from 13 available provinces. However, the responses were categorized into the five main regions of the central region (Riyadh, Ha'il, and Qassim Provinces), northern region (Tabuk, Al-Jouf, and the Northern Borders Provinces), southern region (Najran, Asir, and Jazan Provinces), eastern region (the Eastern Province), and western region (Mecca, Medina, and Al-Bahah Provinces). The participants were also asked whether they had received an influenza vaccine within the past year. Finally, respondents were also asked about how they perceive the risk of COVID-19 on both personal and community levels.

\subsection{Statistical Analysis}

Statistical Package for Social Sciences software version 26.0 (IBM, Inc., Armonk, New York, NY, USA) was used to perform the statistical analysis. Demographic and clinical characteristics of the participants and their perceived risks of COVID-19 were summarized as frequencies and percentages. Univariate unadjusted associations between such characteristics and the intention to get vaccinated were assessed using Pearson's chi-square test. The adjusted associations were explored by performing multinominal logistic regression, which is used to assess the predictors of an outcome variable of two or more categories to a reference category. The dependent variable was participants' intentions to receive the vaccine, and the reference category was the "yes" response. Participants' characteristics that were found to be statistically significant in the univariate analysis were only included in the final regression model as potential predictors. The obtained exponentiated coefficients were interpreted as relative risk ratios (RRRs) and their respective 95\% confidence intervals (95\%CIs). Statistical significance was considered at $p<0.05$.

\section{Results}

\subsection{Demographic Characteristics}

The responses of 3.091 participants were initially recorded. However, some records were excluded due to either a lack of primary outcomes (19 records) or reporting invalid age values $(<18$ years, 24 records). Therefore, the responses of 3048 participants were ultimately included in the subsequent analysis. The majority of respondents were aged $18-44$ years $(85.1 \%)$ and were Saudis $(89.5 \%)$. More than half of the population under study were females $(60.1 \%)$ residing in the western region $(57.0 \%)$ and were currently employed $(52.9 \%$, Table 1). Of the latter group, 305 and 491 respondents declared that they were working completely or partially remotely, representing $18.9 \%$ and $30.5 \%$ of the working population, respectively. 


\subsection{Clinical Characteristics and the Perceived Risk of COVID-19}

In general, less than half of the respondents (41.1\%) had received a flu shot or flu spray within the last year. Of note, 580 respondents $(19.0 \%)$ declared a history of chronic illness. Additionally, 349 respondents (11.5\%) had experienced COVID-19, while the disease had affected family members and friends or coworkers of $32.3 \%$ and $66.0 \%$ of the participants, respectively. Regarding the perceived risk of COVID-19, less than two-thirds of the participants perceived the disease as representing a low to moderate risk to the individual $(63.4 \%)$ and others in the community $(62.3 \%$, Table 2$)$.

Table 1. Demographic characteristics of the participants and their distribution according to intention to be vaccinated $(n=3048)$.

\begin{tabular}{|c|c|c|c|c|c|c|}
\hline \multirow{2}{*}{ Parameter } & \multirow{2}{*}{ Category } & \multirow{2}{*}{$\mathbf{N}(\%)$} & \multicolumn{3}{|c|}{ Intention to Be Vaccinated, $n(\%)$} & \multirow{2}{*}{$p$} \\
\hline & & & Yes $(n=1612)$ & Unsure $(n=817)$ & No $(n=619)$ & \\
\hline \multirow{4}{*}{ Age } & $18-29 y$ & $1331(43.7)$ & $713(53.6)$ & $361(27.1)$ & $257(19.3)$ & 0.079 \\
\hline & $30-44 y$ & $1261(41.4)$ & $638(50.6)$ & $348(27.6)$ & $275(21.8)$ & \\
\hline & $45-59 y$ & 409 (13.4) & $228(55.7)$ & $99(24.2)$ & $82(20)$ & \\
\hline & $\geq 60 y$ & $47(1.5)$ & $33(70.2)$ & $9(19.1)$ & $5(10.6)$ & \\
\hline \multirow{2}{*}{ Gender } & Male & 1217 (39.9) & $779(64)$ & $284(23.3)$ & $154(12.7)$ & $<0.0001$ \\
\hline & Female & $1831(60.1)$ & $833(45.5)$ & $533(29.1)$ & $465(25.4)$ & \\
\hline \multirow{4}{*}{ Education level } & $<$ Secondary education & $42(1.4)$ & $34(81)$ & $5(11.9)$ & $3(7.1)$ & 0.010 \\
\hline & Secondary & $302(9.9)$ & $149(49.3)$ & $80(26.5)$ & $73(24.2)$ & \\
\hline & University & $2104(69)$ & $1118(53.1)$ & $567(26.9)$ & $419(19.9)$ & \\
\hline & Post-graduate & $600(19.7)$ & $311(51.8)$ & $165(27.5)$ & $124(20.7)$ & \\
\hline \multirow{2}{*}{ Nationality } & Saudi & $2729(89.5)$ & $1468(53.8)$ & $738(27)$ & $523(19.2)$ & $<0.0001$ \\
\hline & Non-Saudi & $319(10.5)$ & $144(45.1)$ & $79(24.8)$ & $96(30.1)$ & \\
\hline \multirow{4}{*}{$\begin{array}{l}\text { Current } \\
\text { employment } \\
\text { status }\end{array}$} & Employed-Government & $1157(38)$ & $622(53.8)$ & $311(26.9)$ & $224(19.4)$ & 0.320 \\
\hline & $\begin{array}{c}\text { Employed-Private/self- } \\
\text { employed }\end{array}$ & $530(17.4)$ & $285(53.8)$ & $127(24.0)$ & $118(22.3)$ & \\
\hline & Student & $581(19.1)$ & $314(54)$ & $149(25.6)$ & $118(20.3)$ & \\
\hline & Not working & $780(25.6)$ & $391(50.1)$ & $230(29.5)$ & $159(20.4)$ & \\
\hline \multirow{4}{*}{$\begin{array}{c}\text { Monthly } \\
\text { income (SAR) }\end{array}$} & $<3000$ & $1220(40)$ & $641(52.5)$ & $332(27.2)$ & $247(20.2)$ & 0.067 \\
\hline & $3000-10,000$ & 851 (27.9) & $426(50.1)$ & $228(26.8)$ & $197(23.1)$ & \\
\hline & $>10,000-25,000$ & $856(28.1)$ & $470(54.9)$ & $227(26.5)$ & 159 (18.6) & \\
\hline & $>25,000$ & $121(4)$ & $75(62)$ & $30(24.8)$ & $16(13.2)$ & \\
\hline \multirow{4}{*}{ Household size } & $1-3$ & 495 (16.2) & $260(52.5)$ & $122(24.6)$ & $113(22.8)$ & 0.243 \\
\hline & $4-6$ & $1402(46)$ & $728(51.9)$ & $392(28)$ & $282(20.1)$ & \\
\hline & $7-9$ & 818 (26.8) & $430(52.6)$ & $227(27.8)$ & $161(19.7)$ & \\
\hline & $\geq 10$ & 333 (10.9) & $194(58.3)$ & $76(22.8)$ & $63(18.9)$ & \\
\hline \multirow{5}{*}{$\begin{array}{l}\text { Geographic } \\
\text { region of } \\
\text { residency }\end{array}$} & Western & $1738(57)$ & $916(52.7)$ & $482(27.7)$ & $340(19.6)$ & $<0.0001$ \\
\hline & Eastern & $294(9.6)$ & $154(52.4)$ & $76(25.9)$ & $64(21.8)$ & \\
\hline & Northern & $193(6.3)$ & $93(48.2)$ & $54(28)$ & $46(23.8)$ & \\
\hline & Southern & $329(10.8)$ & $217(66)$ & $71(21.6)$ & $41(12.5)$ & \\
\hline & Central & $494(16.2)$ & $232(47)$ & $134(27.1)$ & $128(25.9)$ & \\
\hline
\end{tabular}

SAR = Saudi Riyal.

\subsection{Vaccination Intention and Associated Factors}

Overall, 1612 participants (52.9\%) indicated that they would receive the SARS-CoV-2 vaccine as soon as it becomes available, $817(26.8 \%)$ were unsure about getting vaccinated, and $619(20.3 \%)$ revealed that they would not receive the vaccine. Unadjusted univariate association analysis showed that the intent to get vaccinated differed significantly by gender $(p<0.0001)$, nationality $(p<0.0001)$, educational attainment $(p=0.010)$, and region $(p<0.0001$, Table 1). Furthermore, compared to their counterparts, vaccination intention was higher among participants who had received an influenza shot as well as those with relatively higher perceived risks for COVID-19 on the personal and community levels (Table 2).

The results of the adjusted multivariate regression analysis are demonstrated in Table 3. Females had less than threefold higher relative likelihood of not intending to receive the vaccine compared to males ( $\mathrm{RRR}=2.70,95 \% \mathrm{CI}, 2.18$ to $3.36, p<0.0001$ ), and the relative likelihood remained significant for "unsure" responses (RRR $=1.69,95 \% \mathrm{CI}, 1.41$ 
to $2.02, p<0.0001)$. In addition, participants who had not received an influenza vaccine had a nearly threefold higher relative likelihood of providing "no" responses ( $R R R=2.63$, $95 \% \mathrm{CI}, 2.12$ to $3.25, p<0.0001)$ and a nearly twofold higher relative likelihood of providing "unsure" responses (RRR $=1.88,95 \% \mathrm{CI}, 1.57$ to $2.24, p<0.0001)$.

Table 2. Medical histories and experiences with COVID-19 among participants and their distribution by intention to be vaccinated $(n=3048)$.

\begin{tabular}{|c|c|c|c|c|c|c|}
\hline \multirow{2}{*}{ Parameter } & \multirow{2}{*}{ Category } & \multirow{2}{*}{ N (\%) } & \multicolumn{3}{|c|}{ Intention to Be Vaccinated, $n(\%)$} & \multirow{2}{*}{$p$} \\
\hline & & & Yes $(n=1612)$ & Not Sure $(n=817)$ & No $(n=619)$ & \\
\hline \multirow{2}{*}{ History of a chronic disease } & No & $2468(81)$ & $1303(52.8)$ & $673(27.3)$ & $492(19.9)$ & \multirow{2}{*}{0.367} \\
\hline & Yes & $580(19)$ & $309(53.3)$ & $144(24.8)$ & $127(21.9)$ & \\
\hline \multirow{2}{*}{ History of COVID-19 } & No & $2699(88.5)$ & $1430(53)$ & $736(27.3)$ & $533(19.7)$ & \multirow{2}{*}{0.061} \\
\hline & Yes & $349(11.5)$ & $182(52.1)$ & $81(23.2)$ & $86(24.6)$ & \\
\hline \multirow{2}{*}{$\begin{array}{l}\text { History of COVID-19 among } \\
\text { family members }\end{array}$} & No & $2064(67.7)$ & $1092(52.9)$ & $561(27.2)$ & $411(19.9)$ & \multirow[b]{2}{*}{0.66} \\
\hline & Yes & $984(32.3)$ & $520(52.8)$ & $256(26)$ & $208(21.1)$ & \\
\hline \multirow{2}{*}{$\begin{array}{l}\text { History of COVID-19 among } \\
\text { friends }\end{array}$} & No & $1035(34)$ & $543(52.5)$ & $271(26.2)$ & $221(21.4)$ & \multirow{2}{*}{0.571} \\
\hline & Yes & $2013(66)$ & $1069(53.1)$ & $546(27.1)$ & $398(19.8)$ & \\
\hline \multirow{2}{*}{$\begin{array}{l}\text { Recently received an influenza } \\
\text { vaccine }\end{array}$} & No & $1794(58.9)$ & $798(44.5)$ & $535(29.8)$ & $461(25.7)$ & \multirow{2}{*}{$<0.0001$} \\
\hline & Yes & $1254(41.1)$ & $814(64.9)$ & $282(22.5)$ & $158(12.6)$ & \\
\hline \multirow{3}{*}{$\begin{array}{l}\text { Perception of risk of COVID-19 } \\
\text { to the individual }\end{array}$} & No & $376(12.3)$ & $37(38.9)$ & $9(9.5)$ & $49(51.6)$ & \multirow{3}{*}{$<0.0001$} \\
\hline & Low to Moderate & $1931(63.4)$ & 967 (50.9) & $551(29)$ & $381(20.1)$ & \\
\hline & High to very high & $741(24.3)$ & $608(57.7)$ & $257(24.4)$ & 189 (17.9) & \\
\hline \multirow{3}{*}{$\begin{array}{l}\text { Perception of risk of COVID-19 } \\
\text { to others }\end{array}$} & No & $95(3.1)$ & $164(43.6)$ & $75(19.9)$ & $137(36.4)$ & \multirow{3}{*}{$<0.0001$} \\
\hline & Low to Moderate & $1899(62.3)$ & $1034(53.5)$ & $556(28.8)$ & $341(17.7)$ & \\
\hline & High to very high & 1054 (34.6) & $414(55.9)$ & $186(25.1)$ & $141(19)$ & \\
\hline
\end{tabular}

Table 3. Predictors of providing "no" and "unsure" responses regarding participants' intent to get vaccinated.

\begin{tabular}{|c|c|c|c|c|c|}
\hline \multirow{3}{*}{ Parameter } & \multirow{3}{*}{ Category } & \multicolumn{4}{|c|}{ Intent to Be Vaccinated } \\
\hline & & \multicolumn{2}{|c|}{ No vs. Yes } & \multicolumn{2}{|c|}{ Not Sure vs. Yes } \\
\hline & & RRR $(95 \%$ CI) & $p$ & RRR $(95 \%$ CI) & $p$ \\
\hline \multirow[b]{2}{*}{ Gender } & Female & $2.70(2.18-3.36)$ & $<0.0001$ & $1.69(1.41-2.02)$ & $<0.0001$ \\
\hline & Male & Ref & & Ref & \\
\hline \multirow{2}{*}{ Nationality } & Saudi & $0.49(0.36-0.66)$ & $<0.0001$ & $0.85(0.63-1.15)$ & 0.304 \\
\hline & Non-Saudi & Ref & & Ref & \\
\hline \multirow{4}{*}{ Educational level } & $<$ Secondary education & $0.16(0.05-0.57)$ & 0.005 & $0.26(0.1-0.68)$ & 0.006 \\
\hline & Secondary & $0.92(0.63-1.34)$ & 0.658 & $0.92(0.66-1.29)$ & 0.632 \\
\hline & University & $0.84(0.65-1.09)$ & 0.183 & $0.88(0.7-1.1)$ & 0.256 \\
\hline & Post-graduate & Ref & & Ref & \\
\hline \multirow{5}{*}{ Geographic location } & Western & $0.78(0.6-1.01)$ & 0.061 & $0.93(0.73-1.19)$ & 0.576 \\
\hline & Eastern & $0.83(0.57-1.23)$ & 0.356 & $0.87(0.61-1.24)$ & 0.445 \\
\hline & Northern & $0.99(0.64-1.53)$ & 0.966 & $1.00(0.66-1.49)$ & 0.982 \\
\hline & Southern & $0.46(0.30-0.69)$ & $<0.0001$ & $0.61(0.43-0.87)$ & 0.006 \\
\hline & Central & Ref & & Ref & \\
\hline \multirow{2}{*}{ Received the influenza vaccine recently } & No & $2.63(2.12-3.25)$ & $<0.0001$ & $1.88(1.57-2.24)$ & $<0.0001$ \\
\hline & Yes & Ref & & Ref & \\
\hline \multirow{3}{*}{ Personal risk of COVID-19 } & High to very high & $0.59(0.35-0.99)$ & 0.046 & $1.05(0.79-3.09)$ & 0.060 \\
\hline & Low to Moderate & $0.45(0.26-0.79)$ & 0.006 & $1.68(0.76-3.7)$ & 0.200 \\
\hline & No & Ref & & Ref & \\
\hline \multirow{3}{*}{ Risk of COVID-19 to others } & High to very high & $0.52(0.38-0.7)$ & $<0.0001$ & $1.16(0.85-1.58)$ & 0.356 \\
\hline & Low to Moderate & $0.63(0.43-0.91)$ & 0.014 & $1.16(0.8-1.67)$ & 0.441 \\
\hline & No & Ref & & Ref & \\
\hline
\end{tabular}

$\mathrm{RRR}=$ Relative risk ratio.

Conversely, the relative likelihood of vaccine refusal was $84 \%$ lower among individuals with less than secondary education compared to individuals with post-graduate degrees ( $R R R=0.16,95 \% C I, 0.05$ to $0.57, p=0.005$ ). Saudis had a $51 \%$ lower relative likelihood of not receiving the vaccine ( $\mathrm{RRR}=0.49,95 \% \mathrm{CI}, 0.36$ to $0.66, p<0.0001)$, and people residing in the southern region were less likely to be hesitant (RRR $=0.46,95 \% \mathrm{CI}, 0.30$ to $0.69, p<0.0001$ ) or uncertain about vaccination ( $\mathrm{RRR}=0.61,95 \% \mathrm{CI}, 0.43$ to $0.87, p=0.006$ ) than those residing in the central region. Finally, people with low to high perceived risk 
of COVID-19 had 37-55\% lower relative likelihood of responding "no" regarding their vaccination intent (Table 3).

\subsection{Reasons for No or Not Sure Responses Regarding Participant's Intention to Get Vaccinated}

The reasons given by participants who replied no or unsure with regard to getting vaccinated are provided in Figure 1, and more detailed descriptive statistics are available in the Supplementary Materials (Tables S1 and S2). Short clinical testing was the most frequently given reason for rejecting vaccination, as indicated by $75.6 \%$ of those who provided no responses. This was followed by concerns about vaccine-related adverse events $(70.4 \%)$, and then a self-perception as having a poor chance of contracting the disease and a perceived lack of vaccine efficacy (53.5\%, Figure 1A).

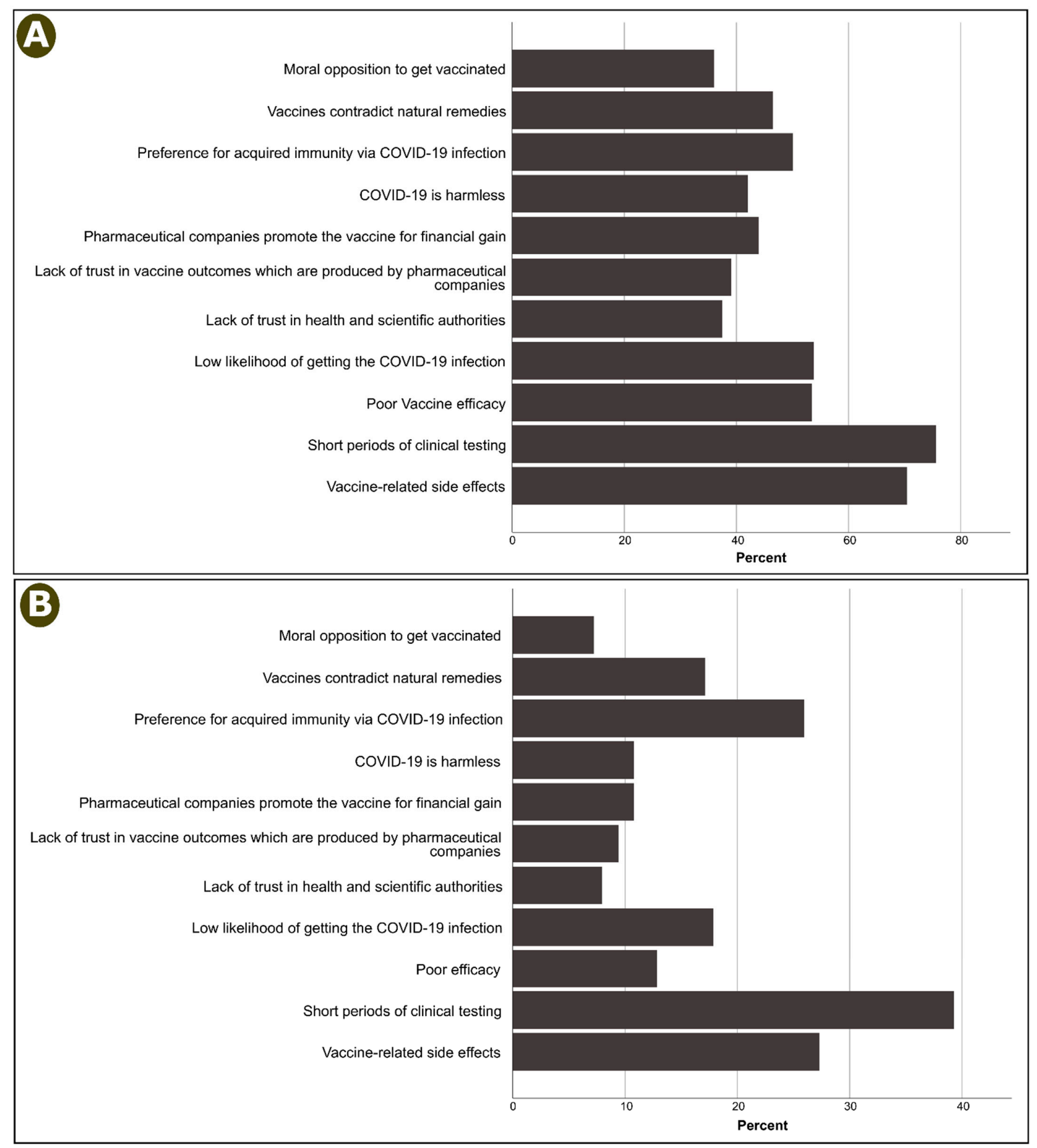

Figure 1. Reasons for hesitancy among participants who answered (A) no or (B) unsure regarding their intention to get vaccinated. 
Among the unsure participants, the most common reasons given for refusing vaccination were short clinical testing period (39.3\%), vaccine side effects $(27.3 \%)$, and preference for acquired immunity via contracting the COVID-19 infection (25.9\%, Figure 1B).

\section{Discussion}

Vaccination is the mainstay public health approach for preventing the spread of infectious diseases; however, vaccines' effectiveness relies on their use. Such an observation can be confirmed by the resurgence of measles and pertussis outbreaks due to widespread anti-vaccine attitudes in recent decades [16,17]. Therefore, vaccination efforts can be undermined by negative attitudes that mediate vaccine refusal, which would threaten the ultimate goal of herd immunity [18]. The present study showed that $47.1 \%$ of adults in Saudi Arabia were unsure or unwilling to get the COVID-19 vaccination, whereas only $52.9 \%$ of individuals intended to get vaccinated. Females and individuals who had not received a flu vaccine within the past year were more likely to refuse vaccination. Conversely, Saudis, participants with a perception of low to high risk of COVID-19, and those who had been vaccinated against influenza were more likely to intend to vaccinate.

The results of the present analysis revealed interesting findings. Vaccine uptake is generally lower in Saudi Arabia than what is reported in other countries. For instance, recent cross-sectional investigations indicated that the proportion of the populations that intended to vaccinate was $91.3 \%$ in China [19], 79.0\% in the United Kingdom [20], 76.5\% in Australia [21], and 53.6-62.2\% in the United States [22,23]. Similarly, recent systematic reviews and meta-analyses have shown that acceptance rates were highest in China and Southeast Asia and were lowest in distinct Arab countries (Kuwait and Jordan) and some European countries, such as Italy and Russia [24,25]. In Saudi Arabia, another Arabicspeaking country, Al-Mohaithef and Padhi [12] conducted a web-based survey among 992 adults residing in four major cities, and the authors found that $62.2 \%$ of participants would be extremely or somewhat likely to get vaccinated. The lower rate of vaccine acceptance in our study indicates a declining trend in participants' intentions.

Similarly, Daly and Robinson [23] also found a significant decline in vaccine acceptance, from $71 \%$ to $53.6 \%$ during the period between April and October 2020 in the United States. Interestingly, in a large web-based study of public individuals, Loomba et al. [26] showed that $54.1 \%$ and $42.5 \%$ of participants from the United States and the United Kingdom, respectively, would "definitely" get the vaccination, but those rates have dropped by $6.2 \%$ and $6.4 \%$, respectively, after exposure to online misinformation about the vaccine. This indicates that the significant temporal decline in vaccination uptake might be explained by exposure to misleading information, conspiracy theories, and other false reports being spread online via social media platforms. Online anti-vaccine movements have already been significantly influencing public individuals' perceptions and attitudes toward vaccinations of all types in the United States [27]. Nevertheless, little is known about such effects in the Saudi community. Therefore, the determinants of the impact of misleading information on individuals' perceptions should be investigated in future studies in order to reduce vaccine refusal rates.

To some extent, the general public's concerns regarding vaccine safety were significant, as shown in our study. Similarly, the top reasons for vaccination refusal in the earlier study in Saudi Arabia [12] included vaccine-related adverse events, concerns about allergic responses, worries about vaccine effectiveness, and preferences for acquired immunity through infection. As could be expected, the vaccines have been developed at unprecedented speeds, with a quick start and multiple development steps being carried out simultaneously before verifying successful outcomes in other steps [28]. This pandemic paradigm of vaccine development has raised concerns regarding the effectiveness and safety of vaccines in the context of short clinical testing times and the lack of reliable longterm outcomes that ensure substantial vaccine acceptance. Hence, short clinical testing and vaccine-related safety concerns were the major drivers of vaccine hesitancy in our analysis. 
Of note, the lack of clinical testing among distinct populations might also mediate vaccine refusal. For example, hesitancy may be apparent due to the lack of evidence-based data regarding the benefits and risks of COVID-19 vaccine among patients with benign or malignant hematological conditions who would potentially exhibit an altered immune response to SARS-CoV-2 vaccines [29]. Similarly, the immune response in patients on hemodialysis is usually characterized by a reduced function of the innate and adaptive immunity, which may lead to hyporesponsiveness to vaccines [30]. Additionally, vaccine responsiveness is unknown among children and adolescents, particularly those with chronic conditions, such as obesity, disability, and chronic diseases [31]. These challenges and uncertainties underline the importance of raising the public's awareness regarding the vaccine until reliable evidence has been established.

Additionally, vaccine refusal was predicted by distinct demographic groups. Females were more likely to oppose vaccination, which is in agreement with other studies [32-34]. Callaghan et al. [33] showed that females refused the vaccine due to concerns about vaccine safety and effectiveness. In contrast, hesitant males were more likely to express financial concerns (the cost of the prospective vaccine). People in the southern region were more likely to accept vaccination than those living in central region provinces. The central region includes Saudi Arabia's capital Riyadh, which, like most capital cities, is highly developed. The literacy rate is very high in Riyadh, and thus our results indicate that educated people have more questions about the vaccine's efficacy because of easy access to the media. Even after the emergence of different strains of the coronavirus, educated people have continued to harbor more doubts. It could be one of the plausible reasons for less acceptance of vaccination in this region. Intriguingly, getting an influenza vaccination was a significant predictor of getting vaccinated against COVID-19, which is consistent with the fact that past behavioral intentions can act as major drivers of future behavior across several health areas [35-37]. Similarly, the perceived risk of COVID-19 has played an important role in participants' intentions, and this is in accord with previous studies demonstrating that the emotional side of risk perception had guided decisions to be vaccinated against influenza [38,39].

Based on these findings, public health experts and decision-makers need to adopt robust strategic plans to encourage vaccine uptake. It is also necessary to ensure that accurate information is communicated to the public through authentic sources who provide such information transparently and correctly. For instance, to address the existing concerns about vaccination, health care providers and the Ministry of Health could convey CDC recommendations using targeted conversations to address public vaccination concerns. In this way, inaccurate health information on social media platforms could be corrected, and data about vaccine effectiveness and safety would be publicly available to individuals. This would eventually promote confidence in the information and be supportive of individuals' decisions regarding vaccination.

The present study employed the largest sample of the Saudi public so far. This might address the rising demand for relevant studies to assess public attitudes in the Middle East [25]. Additionally, we have provided insight into respondents' intentions following the official approval of a number of vaccines, which might fill the gap of knowledge regarding the real community response to vaccines already in place and the temporal changes in individuals' attitudes. However, the inherent limitations of a cross-sectional survey remain problematic, where the reporting bias might have affected outcomes. Additionally, the web-based method might result in different patterns of responses than would be received in a face-to-face design. Moreover, the representation from all five regions of the Kingdom was not equal.

\section{Conclusions}

In conclusion, about half of Saudis are unwilling or undecided about getting the COVID-19 vaccine, representing a significant public health threat and impediment to the goal of attaining herd immunity. Specific demographic groups were more likely to intend 
to vaccinate, such as males, Saudis, individuals with less than a secondary education, residence in the southern region, and individuals with perceived risks of COVID-19. Furthermore, participants who had received the influenza vaccine within the past year were more likely to accept the COVID-19 vaccine. Understanding why individuals may express hesitancy about vaccination is a key factor in designing targeted programs by stakeholders and decision-makers in the national health care system. More specifically, scientific data should be transparently and correctly conveyed to vaccine-hesitant populations to counter the misleading information that might be provided via inauthentic platforms.

Supplementary Materials: The following are available online at https:/ / www.mdpi.com/article/10 $.3390 /$ vaccines 9070798 /s1, Table S1: Reasons for vaccine hesitancy among participants who answered "no" regarding their intentions to get vaccinated $(n=619)$, Table S2: Reasons for vaccine hesitancy among participants who answered "unsure" regarding their intentions to get vaccinated $(n=817)$.

Author Contributions: Conceptualization, S.H.A.; Data curation, S.H.A., M.B., M.W.A., M.R.A., M.M.A., N.A.A. and H.Z.A.; Formal analysis, S.H.A., M.B., M.R.A., M.M.A., N.A.A., H.Z.A. and T.A.; Funding acquisition, S.H.A.; Methodology, S.H.A., M.B., M.W.A., M.R.A., M.M.A., N.A.A., H.Z.A. and T.A.; Project administration, S.H.A.; Resources, M.B., M.W.A., M.R.A., M.M.A., N.A.A. and H.Z.A.; Supervision, M.R.A. and T.A.; Validation, M.B., M.W.A., M.R.A., M.M.A., N.A.A., H.Z.A. and T.A.; Writing—original draft, S.H.A.; Writing—review \& editing, S.H.A., M.B., M.W.A., M.R.A., M.M.A., N.A.A., H.Z.A. and T.A. All authors have read and agreed to the published version of the manuscript.

Funding: This work was funded by the Deanship of Scientific Research (DSR), KAU, Jeddah, under grant No. RG-10-140-42. The authors acknowledge DSR with thanks for their technical and financial support. The funders had no role in the study's design, data collection and analysis, decision to publish, or preparation of the manuscript.

Institutional Review Board Statement: The protocol of the present study was approved by the Research Ethics Committee (REC) of King Abdulaziz University, Jeddah, Saudi Arabia. (Reference No. 235-92-78).

Informed Consent Statement: Written informed consent was obtained and documented from all participants. They were informed about the nature of the study and confidentiality of their responses.

Data Availability Statement: All original data are available in the Department of Family Medicine, King Abdulaziz University, Jeddah, Saudi Arabia.

Conflicts of Interest: The authors declare no conflict of interest.

\section{References}

1. World Health Organization. Weekly Epidemiological Update-2 March 2021. Available online: https://www.who.int/docs/ default-source / coronaviruse / situation-reports /20210302_weekly_epi_update_29.pdf?sfvrsn=91306c8c_5\&download=true (accessed on 7 March 2021).

2. World Health Organization. Saudi Arabia: WHO Coronavirus Disease (COVID-19) Dashboard. Available online: https: / / covid19.who.int/region/emro/country/sa (accessed on 7 March 2021).

3. Baig, M.; Jameel, T.; Alzahrani, S.H.; Mirza, A.A.; Gazzaz, Z.J.; Ahmad, T.; Baig, F.; Almurashi, S.H. Predictors of misconceptions, knowledge, attitudes, and practices of COVID-19 pandemic among a sample of Saudi population and its impact: A cross-sectional study. PLoS ONE 2020, 15, e0243526. [CrossRef]

4. Ahmad, T.; Haroon; Baig, M.; Hui, J. Coronavirus disease 2019 (COVID-19) pandemic and economic impact. Pak. J. Med. Sci. 2020, 36, S73-S78. [CrossRef]

5. Algaissi, A.A.; Alharbi, N.K.; Hassanain, M.; Hashem, A.M. Preparedness and response to COVID-19 in Saudi Arabia: Building on MERS experience. J. Infect. Public. Health 2020, 13, 834-838. [CrossRef]

6. Randolph, H.E.; Barreiro, L.B. Herd immunity: Understanding COVID-19. Immunity 2020, 52, 737-741. [CrossRef] [PubMed]

7. Ahmad, T.; Murad, M.A.; Baig, M.; Hui, J. Research trends in COVID-19 vaccine: A bibliometric analysis. Hum. Vaccines Immunother. 2021, 9, 1-6. [CrossRef]

8. Thunstrom, L.; Ashworth, M.; Finnoff, D.; Newbold, S. Hesitancy towards a COVID-19 Vaccine and Prospects for Herd Immunity. Available online: https:/ / papers.ssrn.com/sol3/papers.cfm?abstract_id=3593098 (accessed on 24 May 2021). [CrossRef]

9. Sherman, S.M.; Smith, L.E.; Sim, J.; Amlôt, R.; Cutts, M.; Dasch, H.; Rubin, G.J.; Sevdalis, N. COVID-19 vaccination intention in the UK: Results from the COVID-19 vaccination acceptability study (CoVAccS), a nationally representative cross-sectional survey. Hum. Vaccines Immunother. 2021, 17, 1-10. [CrossRef] [PubMed] 
10. Faasse, K.; Newby, J. Public perceptions of COVID-19 in Australia: Perceived risk, knowledge, health-protective behaviors, and vaccine intentions. Front. Psychol. 2020, 11. [CrossRef]

11. Rhodes, A.; Hoq, M.; Measey, M.-A.; Danchin, M. Intention to vaccinate against COVID-19 in Australia. Lancet Infect. Dis. 2020, 21, e110. [CrossRef]

12. Al-Mohaithef, M.; Padhi, B.K. Determinants of COVID-19 vaccine acceptance in Saudi Arabia: A web-based national survey. J. Multidiscip. Healthc. 2020, 13, 1657-1663. [CrossRef] [PubMed]

13. Lin, C.A.; Xu, X.; Dam, L. Information source dependence, presumed media influence, risk knowledge, and vaccination intention. Atl. J. Commun. 2021, 2, 53-64. [CrossRef]

14. Sarathchandra, D.; Navin, M.C.; Largent, M.A.; McCright, A.M. A survey instrument for measuring vaccine acceptance. Prev. Med. 2018, 109, 1-7. [CrossRef] [PubMed]

15. Grech, V.; Gauci, C.; Agius, S. Vaccine hesitancy among Maltese healthcare workers toward influenza and novel COVID-19 vaccination. Early Hum. Dev. 2020, 105213. [CrossRef]

16. Benecke, O.; DeYoung, S.E. Anti-vaccine decision-making and measles resurgence in the United States. Glob. Pediatr. Health 2019, 6, 2333794x19862949. [CrossRef]

17. Phadke, V.K.; Bednarczyk, R.A.; Salmon, D.A.; Omer, S.B. Association between vaccine refusal and vaccine-preventable diseases in the United States: A review of measles and pertussis. JAMA 2016, 315, 1149-1158. [CrossRef] [PubMed]

18. Piltch-Loeb, R.; DiClemente, R. The vaccine uptake continuum: Applying social science theory to shift vaccine hesitancy. Vaccines 2020, 8, 76. [CrossRef] [PubMed]

19. Wang, J.; Jing, R.; Lai, X.; Zhang, H.; Lyu, Y.; Knoll, M.D.; Fang, H. Acceptance of COVID-19 vaccination during the COVID-19 pandemic in China. Vaccines 2020, 8, 482. [CrossRef] [PubMed]

20. Neumann-Böhme, S.; Varghese, N.E.; Sabat, I.; Barros, P.P.; Brouwer, W.; van Exel, J.; Schreyögg, J.; Stargardt, T. Once we have it, will we use it? A European survey on willingness to be vaccinated against COVID-19. Eur. J. Health Econ. 2020, 21, 977-982. [CrossRef]

21. Dodd, R.H.; Cvejic, E.; Bonner, C.; Pickles, K.; McCaffery, K.J. Willingness to vaccinate against COVID-19 in Australia. Lancet Infect. Dis. 2020, 21, P318-P319. [CrossRef]

22. Ruiz, J.B.; Bell, R.A. Predictors of intention to vaccinate against COVID-19: Results of a nationwide survey. Vaccine 2021, 39, 1080-1086. [CrossRef]

23. Daly, M.; Robinson, E. Willingness to vaccinate against COVID-19 in the US: Longitudinal evidence from a nationally representative sample of adults from April-October 2020. medRxiv 2020, 60, 766-773. [CrossRef]

24. Lazarus, J.V.; Ratzan, S.C.; Palayew, A.; Gostin, L.O.; Larson, H.J.; Rabin, K.; Kimball, S.; El-Mohandes, A. A global survey of potential acceptance of a COVID-19 vaccine. Nat. Med. 2021, 27, 225-228. [CrossRef] [PubMed]

25. Sallam, M. COVID-19 vaccine hesitancy worldwide: A concise systematic review of vaccine acceptance rates. Vaccines 2021, 9, 160. [CrossRef]

26. Loomba, S.; de Figueiredo, A.; Piatek, S.J.; de Graaf, K.; Larson, H.J. Measuring the impact of COVID-19 vaccine misinformation on vaccination intent in the UK and USA. Nat. Hum. Behav. 2021, 5, 1-12. [CrossRef]

27. Burki, T. The online anti-vaccine movement in the age of COVID-19. Lancet Digit. Health 2020, 2, e504-e505. [CrossRef]

28. Lurie, N.; Saville, M.; Hatchett, R.; Halton, J. Developing COVID-19 vaccines at pandemic speed. N. Engl. J. Med. 2020, 382, 1969-1973. [CrossRef]

29. Sun, C.; Pleyer, C.; Wiestner, A. COVID-19 vaccines for patients with haematological conditions. Lancet Haematol. 2021, 8 , e312-e314. [CrossRef]

30. Combe, C.; Kirsch, A.H.; Alfano, G.; Luyckx, V.A.; Shroff, R.; Kanbay, M.; van der Sande, F.; Basile, C.; The EUDIAL Working Group of the ERA-EDTA. At least 156 reasons to prioritize COVID-19 vaccination in patients receiving in-centre haemodialysis. Nephrol Dial. Transpl. 2021, 36, 571-574. [CrossRef] [PubMed]

31. Cooper, D.M.; Afghani, B.; Byington, C.L.; Cunningham, C.K.; Golub, S.; Lu, K.D.; Radom-Aizik, S.; Ross, L.F.; Singh, J.; Smoyer, W.E. SARS-CoV-2 vaccine testing and trials in the pediatric population: Biologic, ethical, research, and implementation challenges. Pediatr. Res. 2021, 1, 1-5. [CrossRef]

32. McAndrew, S.; Allington, D. Mode and frequency of COVID-19 information updates, political values, and future COVID-19 vaccine attitudes. PsyArXiv 2020. Available online: https:/ / psyarxiv.com/j7srx/ (accessed on 17 July 2021).

33. Callaghan, T.; Moghtaderi, A.; Lueck, J.A.; Hotez, P.J.; Strych, U.; Dor, A.; Fowler, E.F.; Motta, M. Correlates and disparities of intention to vaccinate against COVID-19. Soc. Sci. Med. 2021, 272, 113638. [CrossRef]

34. Reiter, P.L.; Pennell, M.L.; Katz, M.L. Acceptability of a COVID-19 vaccine among adults in the United States: How many people would get vaccinated? Vaccine 2020, 38, 6500-6507. [CrossRef] [PubMed]

35. Brown, D.J.; Hagger, M.S.; Hamilton, K. The mediating role of constructs representing reasoned-action and automatic processes on the past behavior-future behavior relationship. Soc. Sci. Med. 2020, 258, 113085. [CrossRef] [PubMed]

36. Ouellette, J.A.; Wood, W. Habit and intention in everyday life: The multiple processes by which past behavior predicts future behavior. Psychol. Bull. 1998, 124, 54-74. [CrossRef]

37. Sheeran, P.; Conner, M. Degree of reasoned action predicts increased intentional control and reduced habitual control over health behaviors. Soc. Sci. Med. 2019, 228, 68-74. [CrossRef] [PubMed] 
38. Chapman, G.B.; Coups, E.J. Emotions and preventive health behavior: Worry, regret, and influenza vaccination. Health Psychol. 2006, 25, 82. [CrossRef] [PubMed]

39. Weinstein, N.D.; Kwitel, A.; McCaul, K.D.; Magnan, R.E.; Gerrard, M.; Gibbons, F.X. Risk perceptions: Assessment and relationship to influenza vaccination. Health Psychol. 2007, 26, 146. [CrossRef] [PubMed] 